\title{
The Research on the Relations between Involvement Degrees and Online Customers' Behaviors
}

\author{
Rong Yuan ${ }^{1,2}$, Liu Chang Ruo Yu², Kanglin $\mathrm{Wen}^{2} \&$ Shunyong Yang ${ }^{2}$ \\ ${ }^{1}$ Glorious Sun School of Business and Management, Donghua University, Shanghai, China \\ ${ }^{2}$ School of Economics \& Management, Shanghai Institute of Technology, Shanghai, China \\ Correspondence: Yuan Rong, School of Economics \& Management, Shanghai Institute of Technology, Shanghai, \\ China 201418. Tel: 86-1-893-077-0326. E-mail: Yr@sit.edu.cn
}

Received: January 9, 2013

Accepted: February 3, 2014

Online Published: March 16, 2014

doi:10.5430/bmr.v3n2p10

URL: http://dx.doi.org/10.5430/bmr.v3n2p10

\begin{abstract}
Using the method of questionnaire and taking part of university student's portable computers and books expense as an example, this paper explored the heterogeneity of the online consumer buying behavior, an empirical study from the perspective of involvement, and examined the impact of product involvement on online consumer choice behavior. The paper's findings on consumer behavior and brand marketing have a certain reference value.
\end{abstract}

Keywords: E-commerce, Involvement, Online, Consumption

\section{Introduction}

The paper on involvement degrees at the earliest stemmed from the word "Ego Involvement" put forward by American scholars Sherif and Cantril in 1947 during the paper on the theory of society judgments, which is defined as people's attitudes towards various opinions owing to the limit of their statuses and roles (Stenmark, P.; Tinnsten, M.2011). It's the prerequisite of one's response to others' opinions (Lau, Antonio K.W.2011). Initially the involve theory was usually quoted by psychologists during their psychological paper while the early western marketing scholars, normally spreading based on the decision procedures of solving problems, in spite of the fixed distributions made by the mode of customers' behavior in explaining customers' behavior, then applied the involve theory of society judgments paper to the marketing research and expanded this definition, defining it as the relevant or concerning degree of one's feelings of something and customers' different behaviors embodied at different degrees of involvement. (Zaichkowsky, 1985)

\section{Comments on Literature}

With the increasing development of electronic commerce and online shopping, online customers' choosing behaviors get more and more attractions (Svendsen, Mons Freng.2011). Due to the various degrees of products' involvement, customers' emphasis on products or the personal subjective knowledge of products just vary, which determine their active or passive acceptation of products' information and what's more influence the process of purchasing decisions (Hyunjoo Im, 2011). At present the definitions of involvement degrees are the sorts as follows:

Table 1. The Table of the definition of Involvement Degrees

\begin{tabular}{c|c|c}
\hline Time & Scholars & Main Opinions \\
\hline 1947 & Sherif \& Cantril & $\begin{array}{r}\text { Ego involvement is the degree of the relevance between individuals' } \\
\text { feelings to any stimulation and situations and themselves. } \\
\text { decided by personal need and interest }\end{array}$ \\
1969 & $\begin{array}{r}\text { Howard \& Sheth } \\
\text { Mittal }\end{array}$ & $\begin{array}{r}\text { individuals' intended mental state to one's aims or activities, } \\
\text { reflecting one's degree of interests to aims or activities }\end{array}$ \\
1985 & Zaichkowsky & $\begin{array}{r}\text { Andrews } \\
\text { the concerning degree of individuals' feelings to something based on } \\
\text { self-need, values and interests. }\end{array}$ \\
1990 & Engel,Blackwell Miniard & $\begin{array}{r}\text { receivers' inner psychological situation, including attention degree } \\
\text { and the way dealing with information } \\
\text { the level of the personal importance and interests cognized by some } \\
\text { stimulation under certain circumstance } \\
\text { Customers' involvements in different products and purchasing } \\
\text { mission have high and low levels as well as media. }\end{array}$ \\
\hline
\end{tabular}

Resource: XiaoSong Dong, JiHao Zhang, Summarization of the Research on Customers' Involvement Degree, Business Time, the 12th issue of 2009. 
In addition, Cees, J. P. M. de Bont (1995) roughly defined involvement degree as a stimulation or situational self-caring properties or felt self-caring properties; In Zaichkowsky's (1985) research it was defined as "A perceptive self-caring property to something based on its inner need, value system and interests". Pirjo (1994) referred that considering the realm where the concept involvement degree was applied, there would be many kinds of involvement degrees. For example, there existed high and low involvement degrees of products, questions, customers, media, learning process, circumstance, perceive structure and etc. In further research and practical application, people tend not to exercise the word "Involvement Degree" alone, but distinguish various types of involvement degrees. Antil (1984) held the view that the characteristic of stimulation after customers themselves explained really determines whether the involvement degree is high or low regardless of the involvement degree or situational involvement degree or media's involvement degree. Individuals' explanation to various types of stimulations, instead of stimulations themselves (such as products, brands and etc.), just authentically have a conclusive effect. Although people are faced with the same type of stimulation, the involvement level it has produced may as well vary. Antil has some products detailed studied such as cars, diamonds, stereos, watches, tires, flashlights, sun blocks, cigarettes and etc., with a result demonstrating that the diversity of involvement degrees in the categories of products is far more than the products' categories themselves. According to this opinion, that's to say, no matter which abstract category of involvement degree is, the final results formed by accepting different types of stimulations embody fundamentally whether it's high or low. All categories of involvement degrees' subjects are the same involvement of "human" with various stimulations (.Carbonell, Pilar 2012). Therefore, W. Beanie Joseph (1984) held the view that it's the capacities consumers as subjects are endowed with to involve in instead of the inner aspects of stimulations that make people involved, thus involvement degrees manifest the fluctuating changes aroused by the variety of consumers and products. Based on the statement above, the text puts forward the following hypothesizes:

H1: As for products with high involvement degrees, consumers tend to purchase them offline to evade risks;

H2: Consumers with various dependence degrees on Internet have different comments and consciousness on the online shopping behaviors.;

H3: The motivations driving consumers to purchase online distinguishes owing to different degrees;

H4: The reasons why consumers are driven to purchase online vary between consumers with different involvement degrees.

\section{Analysis of Empirical Data}

In terms of the paper on the relations between involvement degrees and online consumer behavior, the article accomplishes by selecting typical sample, performing empirical data analysis, and making use of factor analysis to test the above assumptions.

\subsection{Studying methods and framework}

The paper reflects the differences between the consumption of online consumers via questionnaire research and analyzing the mean value between groups with the help of Independence Sample T Test. The paper indicates that the products' prices has the rather larger influence on the involvement degrees and generally speaking, the more the possible risks felt by consumers are, the more involvement degrees are, otherwise, the less (Stenmark, P.2011). Thus, products with higher price have higher involvement degrees. Conversely, products with lower price have lower involvement degrees. According to this, on the division of different involvement degrees, the paper has divided products studied into two types: Questionnaire A involves the type representing high involvement degree setting laptops as example while questionnaire B involves the type representing low involvement degree setting books as example. In view of the above, the objects of the research are divided into two large groups. Due to the existing variant items found via T-testing, the two large groups above are divided into four groups in all according to online and offline purchasing while the variant items are obtained in the process of choosing the online shopping groups from every large group and then the research compares the results gained during the twice tests with rejecting the same items involved. Thus, the remaining item in the second T-test is the items affected by involvement degrees when consumers choose online consumption. At the same time, the samples are divided on the basis of high and low internet dependence degrees, the high or low frequency online shopping and more or less consumption amount.

\subsection{Survey's objects and samples' confirmation}

The paper is aimed at discovering the differences between various online behaviors consumers perform when facing products with different involvement degrees, such as information searching, choosing evaluation, purchasing determination, evaluation after purchasing and so on and analyzing their characteristics of their purchasing behaviors and ordinary habits and frequency of surfing on the internet and favor of online consumption, which are intended to supply regular data references for the aspects of marketing strategies, namely, the design of related products, 
information release, advertisement design and launch ,trading process, services after sales and so on. The undergraduates of the universities in Shanghai, which are chosen as the research's object have comparatively high intellectual level, are familiar with the application and operation of computers and internet and are capable of fast reading, surfing some English websites and well accepting new stuff, which may correspond with the characteristics of the main receivers of online consumption.

\subsection{Design of questionnaires}

The questionnaires, taking Zaichkowsky's asked items of involvement degrees for developing and balancing products as references, primarily involves the ways of information searching and the spots of purchasing when consumers purchase some kind of products and the paper adopts the five-grade marking system scale to survey the consciousness and evaluation of online consumption.

\subsection{Settlement and analysis of Data}

\subsubsection{Overview of the samples}

The objects of the questionnaires are the undergraduate students from universities in Shanghai Normal University, Shanghai University of Commerce and etc., mainly via handing out paper questionnaires and E-mails. Until June, 2012 , the number has summed to 500 , returning 412 , of which 384 are valid and the recycling rate is $67 \%$, which is composed of 216 questionnaires A and 168 questionnaires B.

\subsubsection{Data analysis}

\subsubsection{Scale reliability}

The questionnaires adopt Likert Scale to firstly analyze the reliability of the scale, so as to test the inner consistence of every sub item in the scale. The reliability analysis employs the common Cronbach's $\alpha$ to make the judgment.

Table 2. The Table of Scale Reliability

\begin{tabular}{c|c}
\hline Cronbach's $\boldsymbol{\alpha}$ & The number of sub items \\
\hline 0.7858 & 25 \\
\hline
\end{tabular}

As the table above shows, $\alpha=0.7858$. It's commonly recognized that if the Cronbach's $\alpha$ is between 0.7 and 0.8 , it demonstrates that the scale needs modification in case of losing its value. Through deeper reliability testing, the item' I can purchase the products I'm not willing to go shopping to purchase on the Internet. ' is eliminated to raise the Cronbach's $\alpha$ up to 0.8226 , which can meet the requirements.

Table 3 The Testing Table of Scale Reliability

\begin{tabular}{c|c|c|c|c}
\hline The Items & $\begin{array}{c}\text { The Mean Value of } \\
\text { the Scale without } \\
\text { the Item }\end{array}$ & $\begin{array}{c}\text { The Variance of the } \\
\text { Scale without the } \\
\text { Item }\end{array}$ & $\begin{array}{c}\text { The Relevance of } \\
\text { the Item and the } \\
\text { Entire }\end{array}$ & $\begin{array}{c}\text { The Cronbach's oof } \\
\text { the Scale without } \\
\text { the Item }\end{array}$ \\
\hline 1 & 77.4635 & 93.9777 & -0.0915 & 0.7985 \\
2 & 77.2448 & 92.7513 & -0.0135 & 0.7934 \\
3 & 77.6094 & 82.0403 & 0.5521 & 0.7654 \\
4 & 77.6823 & 84.2912 & 0.4613 & 0.7712 \\
5 & 77.4479 & 83.8611 & 0.4884 & 0.7697 \\
6 & 77.651 & 93.7886 & -0.0821 & 0.8002 \\
7 & 78.2656 & 82.2275 & 0.6043 & 0.7638 \\
8 & 77.599 & 84.6603 & 0.4291 & 0.7728 \\
9 & 78.6563 & 84.499 & 0.4501 & 0.7718 \\
10 & 78.7083 & 81.9878 & 0.556 & 0.7652 \\
11 & 78.0313 & 80.8158 & 0.5907 & 0.7624 \\
12 & 77.849 & 98.6943 & -0.3447 & 0.7905 \\
13 & 78.5052 & 80.7853 & 0.5119 & 0.7662 \\
14 & 78.2917 & 83.0454 & 0.3924 & 0.7744 \\
15 & 78.6406 & 82.4827 & 0.5242 & 0.767 \\
16 & 78.6146 & 79.9135 & 0.5997 & 0.761 \\
17 & 78.4115 & 78.9659 & 0.6421 & 0.758 \\
18 & 77.1406 & 90.3833 & 0.1376 & 0.787 \\
19 & 77.4531 & 93.5371 & -0.0611 & 0.7939 \\
20 & 77.901 & 86.1839 & 0.4633 & 0.7731 \\
21 & 77.1458 & 90.4498 & 0.1392 & 0.7867 \\
22 & 78.3906 & 85.7262 & 0.504 & 0.7715 \\
23 & 78.1354 & 83.0287 & 0.5737 & 0.7659 \\
24 & 78.3438 & 84.5828 & 0.5815 & 0.7681 \\
25 & 78.8177 & 103.909 & -0.6012 & 0.8226 \\
\hline
\end{tabular}




\subsubsection{Hypothesizes test}

H1: As for products with high involvement degrees, consumers tend to purchase them offline.

Table 4. Questionnaire A: The Statistics of the Sample Result of purchasing Laptops

\begin{tabular}{c|c|c|c|c}
\hline & Online Gathering & Offline Gathering & $\begin{array}{c}\text { Both Online and } \\
\text { Offline Gathering }\end{array}$ & Sum \\
\hline Online Purchase & $8(3.70 \%)$ & $20(9.26 \%)$ & $24(11.11 \%)$ & $52(24.07 \%)$ \\
Offline Purchase & $32(14.81 \%)$ & $44(20.37 \%)$ & $88(40.74 \%)$ & $164(75.93 \%)$ \\
\hline
\end{tabular}

As it can be seen from the table A, the mode focuses on the fourth column in the table, declaring that the majority of the samples investigated (composing $40.74 \%$ of the total sample) may choose to search for related information via online and offline at the same time when purchasing laptops and at last purchase them at the entity shops. Through vertical comparison, it can be concluded that in the samples investigated, the number of people choosing to purchase laptops offline is more than the number of people choosing purchasing online. It can be seen through lateral comparison, the majority of the samples may choose to search for the information about the products both online and offline instead of being dependent on the ways of surfing on the websites related to products or go directly to the entity shops for looking at samples. The table above proves the hypothesis H1: As for products with high involvement degrees, consumers tend to purchase them offline.

Table 5. Questionnaire B The Statistics of the Sample Result of purchasing Bestsellers

\begin{tabular}{c|c|c|c|c}
\hline & $\begin{array}{c}\text { Online } \\
\text { Gathering }\end{array}$ & $\begin{array}{c}\text { Offline } \\
\text { Gathering }\end{array}$ & $\begin{array}{c}\text { Both Online and } \\
\text { Offline Gathering }\end{array}$ & Sum \\
\hline Online Purchase & $46(27.38 \%)$ & $30(17.86 \%)$ & $18(10.71 \%)$ & $94(55.95 \%)$ \\
Offline Purchase & $14(8.33 \%)$ & $40(23.81 \%)$ & $20(11.90 \%)$ & $74(44.05 \%)$ \\
\hline
\end{tabular}

From the table B it cannot be found that there exist extraordinarily apparent differences, not as the situation that more than $40 \%$ of the entire prefer to purchase laptops on a only way. In addition, through vertical and lateral comparisons, there still exist no comparatively apparent differences. Nevertheless, one point, which can be found from the table B, is that consumers having an alternative in gathering information online about products prefer to directly purchase online while consumers choosing to collect information offline tend to purchase offline.

H2: Consumers with various dependence degrees on Internet have different comments and consciousness on the online shopping behaviors.

In order to research the difference of the online consumption of consumers more deeply, the samples are subdivided and the results of the groups are as follows:

Table 6. The Grouping Situation of the Samples

\begin{tabular}{|c|c|c|}
\hline \multirow{6}{*}{ The Laptop Group } & Online gathering \& purchasing & Group1 \\
\hline & Offline gathering \& online purchasing & Group2 \\
\hline & Both online and offline gathering \& online purchasing & Group3 \\
\hline & Online gathering and offline purchasing & Group4 \\
\hline & Offline gathering \& purchasing & Group5 \\
\hline & Both online and offline gathering $\&$ offline purchasing & Group6 \\
\hline \multirow{6}{*}{ The Bestseller Group } & Online gathering \& purchasing & Group7 \\
\hline & Offline gathering \& online purchasing & Group8 \\
\hline & Both online and offline gathering \& online purchasing & Group9 \\
\hline & Online gathering and offline purchasing & Group 10 \\
\hline & Offline gathering \& purchasing & Group11 \\
\hline & Both online and offline gathering \& offline purchasing & Group 12 \\
\hline
\end{tabular}

The paper defines the people collecting products' information and making the purchasing decision both online as consumers highly dependent on the Internet while the people collecting products' information and making the purchasing decision both offline as Consumers' lowly dependent on the Internet. To begin, the Independent-Samples $\mathrm{T}$ is performed to the two types of people, namely the G1+G7 and the G5+G11 in the table 3.4.5 are compared, finding that there exist discrepant elements: 
Table 7. High (Low) internet dependence groups' different consciousness of online consumption

\begin{tabular}{c|c|c|c|c}
\hline Elements & F & t & $\begin{array}{c}\text { The Mean Value of } \\
\text { G1+G7 }\end{array}$ & $\begin{array}{c}\text { The Mean Value } \\
\text { of G5+G11 }\end{array}$ \\
\hline The Convenience of Online Purchasing & 4.608 & 9.04 & 3.846 & 2.750 \\
The Prices of Products & 0.835 & 6.775 & 4.139 & 3.488 \\
The Safety of Online Purchasing & 4.94 & 10.256 & 4.269 & 2.232 \\
The Interaction of Online Purchasing & 5.436 & 6.914 & 4.123 & 3.421 \\
The Categories and Information of Products & 2.221 & 9.004 & 4.185 & 3.257
\end{tabular}

As it can be seen from the table above, not considering the involvement degrees, high (Low) internet dependence groups' consciousness of online consumption present comparatively large differences and through the comparison of mean value it can be concluded that high internet dependence group holds the view that online consumption is convenient and has high degree of security while the categories of products on the Internet are rich and have low prices. Besides, online consumption performs well in interaction, making it able to offer worthwhile suggestions for the consumers during the process of purchasing.

H3: The motivations driving consumers to purchase online distinguishes owing to different degrees.

In order to more concretely embody whether the differences of two groups of investigators' online consumption decisions are influenced or not, the paper will find out the effects of the involvement degree via multiple comparison among groups.

The comparison of online purchasing group with low involvement degree $(\mathrm{G} 1+\mathrm{G} 2+\mathrm{G} 3$ and $\mathrm{G} 7+\mathrm{G} 8+\mathrm{G} 9)$

Table 8 . The differences between the online purchasing group with high and low involvement degree

\begin{tabular}{c|c|c|c|c}
\hline Elements & F & t & $\begin{array}{c}\text { The Mean value } \\
\text { of G1+G2+G3 }\end{array}$ & $\begin{array}{c}\text { The Mean value } \\
\text { of G7+G8+G9 }\end{array}$ \\
\hline The Prices of Products & 1.290 & 4.335 & 4.221 & 3.755 \\
The Categories and Information of products & 0.032 & 5.165 & 4.331 & 3.796 \\
\hline
\end{tabular}

The result of the test demonstrates that consumers think that products with high involvement degrees are cheaper than those with low involvement degrees when purchasing online. What's more, the categories of the products sold on the Internet and the information the franchisors offer with high involvement degree are richer than those with low involvement.

(1) The comparison of online purchasing group with high or low involvement degrees $(\mathrm{G} 4+\mathrm{G} 5+\mathrm{G} 6$ and $\mathrm{G} 10+\mathrm{G} 11+\mathrm{G} 12)$

Table 9. The differences in the consuming consciousness of purchasing groups with high/ low involvement degrees

\begin{tabular}{c|c|c|c|c}
\hline Elements & F & t & $\begin{array}{c}\text { The Mean Value of } \\
\text { G4+G5+G6 }\end{array}$ & $\begin{array}{c}\text { The Mean Value of } \\
\text { G10+G11+G12 }\end{array}$ \\
\hline $\begin{array}{c}\text { The Convenience of Online } \\
\text { Purchasing }\end{array}$ & 0.636 & -7.621 & 2.655 & 3.234 \\
$\begin{array}{c}\text { The Categories and } \\
\text { Information of Products } \\
\text { The Safety of Online } \\
\quad \begin{array}{c}\text { Purchasing } \\
\text { The Interaction of Online } \\
\text { Purchasing }\end{array}\end{array}$ & 0.007 & -4.654 & 3.179 & 3.530 \\
\hline
\end{tabular}

The result of the test demonstrates that consumers choosing offline purchasing think that offline purchasing is more convenient than online purchasing and online purchasing is not that of safety. Besides, the alternative categories of products and the information are richer and purchasing offline can make sellers much better communicate with other consumers.

Through the testing results of (1) and (2), it can be found that there are three elements leading to consumers not to purchase on the Internet: 'The Convenience of Online Purchasing', 'The Safety of Online Purchasing' and 'The Interaction of Online Purchasing' and it displays apparent differences between products with high involvement degree and products with low involvement degree. When consumers purchase products with low involvement degree, they think online consumption is convenient, safe and with high interaction. However, products with high involvement are on the contrary. 
(2) The comparison of online collecting information group with high or low involvement degrees (G1+G4 and $\mathrm{G} 7+\mathrm{G} 10)$

Table 10. The differences in the collecting information groups with high or low involvement degrees

\begin{tabular}{c|c|c|c|c|c}
\hline Elements & F & t & Sig. (2-tailed) & $\begin{array}{c}\text { The Mean Value } \\
\text { of G1+G4 }\end{array}$ & $\begin{array}{c}\text { The Mean Value } \\
\text { of G7+G10 }\end{array}$ \\
\hline $\begin{array}{c}\text { The Convenience of Online } \\
\text { Purchasing }\end{array}$ & 1.367 & -3.238 & 0.002 & 3.175 & 3.656 \\
$\begin{array}{c}\text { The Categories and } \\
\text { Information of Products } \\
\text { The Safety of Online } \\
\quad \begin{array}{c}\text { Purchasing } \\
\text { The Interaction of Online } \\
\text { Purchasing }\end{array}\end{array}$ & 5.354 & -2.395 & 0.021 & 3.920 & 3.530 \\
\hline
\end{tabular}

The result of the test demonstrates that the consumers making their purchasing decisions via gathering products' information on the Internet think that on the Internet the products with high involvement degree are richer in the information and categories than those with low involvement degree. However, purchasing products with low involvement degree is safer than those with high involvement degree. In addition, in their opinion, purchasing products with low involvement degrees, on one hand, can attain more experiences and suggestions from others to assist them to make decisions; on the other hand, is better in interaction than those with high involvement.

The comparison of online collecting information \& offline purchasing group with high or low involvement degrees (G4+G6 and G10+G12)

Table 11. The differences in the consciousness of the online collecting \& offline purchasing group with high or low involvement degrees of online consumption

\begin{tabular}{c|c|c|c|c|c}
\hline Elements & F & t & Sig. (2-tailed) & $\begin{array}{c}\text { The Mean Value } \\
\text { of G4+G6 }\end{array}$ & $\begin{array}{c}\text { The Mean Value } \\
\text { of G10+G12 }\end{array}$ \\
\hline $\begin{array}{c}\text { The Convenience of Online } \\
\text { Purchasing }\end{array}$ & 2.365 & -5.103 & 0.000 & 2.847 & 3.275 \\
$\begin{array}{c}\text { The Safety of Online } \\
\text { Purchasing }\end{array}$ & 0.628 & -8.16 & 0.000 & 2.076 & 3.015 \\
$\begin{array}{c}\text { The Interaction of Online } \\
\text { Purchasing }\end{array}$ & 0.090 & -5.234 & 0.000 & 3.046 & 3.686 \\
\hline
\end{tabular}

The result of the test demonstrates that consumers gathering information online and purchasing products offline think that purchasing offline is more convenient than online. Nevertheless, purchasing products with high involvement degree online is of great risk and bad in safety. Meanwhile they hold the opinion that the interaction of online purchasing of products with low involvement degree is stronger than those with high involvement degree.

Through the testing results of (3) and (4), it can be found that after consumers gather information on the Internet, an element resulting in their not choosing to purchase online is 'The Categories and Information of Products'. Online consumption is a brand new way of purchasing (Nicolajsen, Hanne Westh2011), however, consumers just can't find information about all the products in the entity shops on the Internet, which is a significant element affecting consumers choose whether to purchase online or not as well.

(3) The comparison of offline collecting information and purchasing group with high or low involvement degrees (G5 and G11)

Table 12. The differences in the consciousness of the online collecting \& purchasing group with high or low involvement degrees of online consumption

\begin{tabular}{c|c|c|c|c|c}
\hline Elements & F & t & Sig. (2-tailed) & $\begin{array}{c}\text { The Mean } \\
\text { Value of G5 }\end{array}$ & $\begin{array}{c}\text { The Mean } \\
\text { Value of G11 }\end{array}$ \\
\hline $\begin{array}{c}\text { The Convenience of Online } \\
\text { Purchasing }\end{array}$ & 14.080 & -8.338 & 0.000 & 2.341 & 3.200 \\
$\begin{array}{c}\text { The Categories and Information of } \\
\text { Products }\end{array}$ & 0.867 & -4.959 & 0.000 & 3.000 & 3.540 \\
The Safety of Online Purchasing & 5.292 & -11.918 & 0.000 & 1.523 & 3.013 \\
\hline
\end{tabular}

The result of the test demonstrates that consumers making their decisions only via gathering information offline think that when purchasing products with high involvement degree, they tend to find the categories and information of 
products on the Internet poor. Besides, purchasing products with high involvement degree is not that convenient and less safe.

H4: The reasons why consumers are driven to purchase online vary between consumers with different involvement degrees.

According to the questionnaires, the sample is divided into different groups in the light of the high or low online consumption frequency and amount with the intention of respectively comparing the discrepancies between, on one hand, the group of high online consumption frequency and of low online consumption frequency, on the other hand, the group of high online consumption amount and of low online consumption amount.

\section{The Limit and Suggestions of the Research}

With limited number of samples, the sampling territorial scope of the research is restricted to several universities in Shanghai and owing to the various sampling amount of the universities, the confirmation of the two types of products' differences remain, which to some extent has an effect on the capacity of the result in popularization. The subsequent researches are supposed to be thought about comprehensively in sampling to decrease deviation.

In order to probe the impact of products with different involvement degrees on consumers' purchasing behavior, the paper covers two categories of products representing high involvement degrees, the laptop and low involvement degrees, books. Hence, the range of the products is limited. Furthermore, the college students characterized as the sole sample consists mainly the target group of the paper. Therefore, the following researches should be expanded in the groups under investigation, covering different categories of online consumption groups as much as possible, so as to obtain a more objective and comprehensive data.

In fact, the products' involvement degrees are not only reflected in the online purchasing process, but are reflected in the daily life (Jung, H.S.2012). In addition, in order to facilitate the measurement, the paper, without involving indirect measurements, only takes the direct measuring method put forward by KaPferer and Laurent in 1992 as references. Therefore, the future researches can be considered, from multiple angles, in studying the impact of products' involvement degrees on online consumption.

\section{Conclusion}

H1: As for products with high involvement degrees, consumers tend to purchase them offline.

The hypothesis 'As for products with high involvement degrees, consumers tend to purchase them offline. ' is established. The paper adopts laptop as the product with high involvement degree, with a result displaying that the reason why consumers choosing to purchase laptops offline are more than those purchasing online is that consumers think that purchasing products with high involvement degrees online is not convenient and bad in safety. By means of the result it can be conjectured that consumers tend to purchase products with high involvement degrees offline.

H2: Consumers with various dependence degrees on Internet have different comments and consciousness on the online shopping behaviors.

The hypothesis 'Consumers with various dependence degrees on Internet have different comments and consciousness on the online shopping behaviors. ' is established. The high- network-dependent consumers and low-network-dependent consumers' perception of online consumption display apparent differences. The highnetwork-dependent consumers think that online consumption is convenient, of high safety, and the categories of the products online are rich and the price is low. In addition, in their opinion, online consumption has a very strong interaction.

H3: The motivations driving consumers to purchase online distinguishes owing to different degrees.

The hypothesis 'The motivations driving consumers to purchase online distinguishes owing to different degrees. ' is established. As for the products with different involvement degrees, the cause resulting in consumers' not purchasing online is the online consumption's convenience, safety and interaction and the discrepancy embodied in the products with different involvement degrees. To wit, consumers regard online consumption as a convenient, safe and powerful in interaction way when purchasing products with low involvement degrees. For the products with high involvement degrees, the results tend to be on the contrast.

H4: The reasons why consumers are driven to purchase online vary between consumers with different involvement degrees.

The hypothesis 'The reasons why consumers are driven to purchase online vary between consumers with different involvement degrees. ' is not established. The result of the paper cannot prove the establishment of H4. Nevertheless, 
it's extremely meaningful for the paper on the high frequency group of online purchasing just in that this type of people have the tendency of utilizing internet instruments and obtain more opportunities to be accessible to online advertisements and publications, making it of great help for the net-franchisers to perform marketing schemes.

\section{References}

Antonio K.W. Lau. (2011). Supplier and customer involvement on new product performance: Contextual factors and an empirical test from manufacturer perspective, Industrial Management \& Data Systems, Vol. 111 Iss: 6, pp.910 - 942. http://dx.doi.org/10.1108/02635571111144973

Antony Potter, Benn Lawson. (2013). Help or Hindrance? Causal Ambiguity and Supplier Involvement in New Product Development Teams. Journal of Product Innovation Management. Vol 30, Iss 4, pages 794-808, July 2013. http://dx.doi.org/10.1111/jpim.12027

Carbonell, Pilar; Rodriguez-Escudero. (2012). Ana I.; Pujari, Devashish. (2012). Performance effects of involving lead users and close customers in new service development. Journal of Services Marketing vol. 26 Iss 7 October 05, 2012. p. 497-509. http://dx.doi.org/10.1108/08876041211266440

Hyunjoo Im, Young Ha. (2011). The effect of perceptual fluency and enduring involvement on situational involvement in an online apparel shopping context, Journal of Fashion Marketing and Management, Vol: 15 Iss: 3

Jung, H.S.; Yoon, H.H. (2012). Why do satisfied customers switch? Focus on the restaurant patron variety-seeking orientation and purchase decision involvement. International Journal of Hospitality Management vol. 31 Iss 3 September, p.875-884. http://dx.doi.org/10.1016/j.ijhm.2011.10.006

Lau, Antonio K.W. (2011). Supplier and customer involvement on new product performance: Contextual factors and an empirical test from manufacturer perspective. Industrial Management \& Data Systems vol. 111 Iss 6 June 28. p. $910-942$.

Lorena Blasco-Arcas, Blanca Hernandez-Ortega, Julio Jimenez-Martinez. (2014). "The online purchase as a context for co-creating experiences. Drivers of and consequences for customer behavior. Internet Research, Vol. 24 Iss: 3.

Nicolajsen, Hanne Westh; Scupola, Ada. (2011). Investigating Isss and challenges for customer involvement in business services innovation. Journal of Business \& Industrial Marketing vol. 26 Iss 5 June 14, p. 368-376 3.

Stenmark, P.; Tinnsten, M.; Wiklund, H. (2011). Customer involvement in product development: Experiences from Scandinavian outdoor companies. Procedia Engineering vol. 13. p. 538-543. http://dx.doi.org/10.1016/j.proeng.2011.05.127

Svendsen, Mons Freng; Haugland, Sven A.; Gronhaug, Kjell; Hammervoll, Trond. (2011). Marketing strategy and customer involvement in product development. European Journal of Marketing vol. 45 Iss 4 April 05. p. 513-530. http://dx.doi.org/10.1108/03090561111111316 